\title{
Cooperative wind observation in the upper mesosphere and lower thermosphere with foil chaff technique, the MU radar, and Yamagawa MF radar
}

\author{
Y. Murayama ${ }^{1}$, K. Igarashi ${ }^{1}$, I. Nishimuta ${ }^{1}$, R. Yamazaki ${ }^{1}$, K.-I. Oyama ${ }^{2}$, T. Tsuda ${ }^{3}$, \\ T. Nakamura ${ }^{3}$, S. Fukao ${ }^{3}$, H.-U. Widdel ${ }^{4}$, and K. Schlegel ${ }^{4}$ \\ ${ }^{1}$ Communications Research Laboratory, Koganei, Tokyo 184-8795, Japan \\ ${ }^{2}$ Institute of Space and Astronautical Science, Sagamihara, Kanagawa 229-8510, Japan \\ ${ }^{3}$ Radio Atmospheric Science Center, Kyoto University, Uji, Kyoto 611-0011, Japan \\ ${ }^{4}$ Max-Planck-Institut für Aeronomie, Katlenburg-Lindau, Germany
}

(Received August 4, 1998; Revised June 9, 1999; Accepted June 9, 1999)

\begin{abstract}
An in-situ rocket technique using foil chaff is used to observe wind fields in the mesosphere and lower thermosphere (80-98 km in altitude). We launched two micro-rockets at 1200 and 1315 UT on 14 January 1997 from Uchinoura, Japan $\left(31^{\circ} \mathrm{N}, 131^{\circ} \mathrm{E}\right)$. The MU radar (MUR; $\left.35^{\circ} \mathrm{N}, 136^{\circ} \mathrm{E}\right)$ and the Yamagawa MF $\operatorname{radar}\left(\mathrm{MFR} ; 31^{\circ} \mathrm{N}, 131^{\circ} \mathrm{E}\right)$ simultaneously observed winds at the same heights by means of a meteor scattering and partial reflection echo from the ionosphere received by spaced antennas, respectively. The chaff and MFR winds generally agree well at 80$88 \mathrm{~km}$, while MFR data were missing at the heights $>88 \mathrm{~km}$. In the chaff, MFR, and the MUR winds, we have found a coherent structure likely due to a large-scale gravity wave. The chaff results suggest that wind fluctuations with a vertical scale of $\sim 2 \mathrm{~km}$ at $82-85 \mathrm{~km}$ are quite consistent with gravity wave motions. It is noteworthy that a qualitative agreement is found between the chaff descent speed fluctuations and the wave-induced vertical component, although those vertical velocities are quantitatively inconsistent. On some special occasions chaff velocity might be affected by another process, of which tentative candidates are an apparent motion of the strong echo point in a chaff cloud, and an internal mesospheric "bore".
\end{abstract}

\section{Introduction}

In recent years, the importance of studies of the mesosphere and lower thermosphere (MLT) region has been stressed. An international research initiative; PSMOS (Planetary Scale Mesopause Observing System) has been promoting intensive efforts to study the MLT region. However, precision techniques to observe this height region are quite limited. This is especially so in regard to in-situ measurements. These are important because remote-sensing techniques such as clear-air radars sometimes involve uncertainty in their measurements (e.g., Reid, 1996). The foil chaff is one of in-situ techniques that directly measures MLT wind velocity. A cloud of foil chaff, which consists of many metalized plastic film pieces, descends relatively slowly at MLT heights with descent speed of $\sim 20$ and $<10 \mathrm{~m} / \mathrm{s}$ at 90 and $80 \mathrm{~km}$, respectively, in comparison with that of a passive falling sphere of $>500 \mathrm{~m} / \mathrm{s}$ at $80-90 \mathrm{~km}$. The foil chaff cloud motion is used to determine wind velocity as well as fine structures of the wind fields which radar or other techniques may be difficult to achieve (e.g., Wu and Widdel, 1992).

On the other hand, to observe MLT winds on a temporally continuous basis, the MF radar is an important technique. The MF radar utilizes partial reflection echoes from the ionospheric $\mathrm{D}$ region and by the use of spaced antenna (SA method) observes horizontal wind velocity throughout

Copy right(c) The Society of Geomagnetism and Earth, Planetary and Space Sciences (SGEPSS); The Seismological Society of Japan; The Volcanological Society of Japan; The Geodetic Society of Japan; The Japanese Society for Planetary Sciences. the day. More than twenty MF radars now operate at various sites at low, mid and high latitudes such as Pontianak $\left(0^{\circ}\right)$, Christmas Island $\left(2^{\circ} \mathrm{N}\right)$, Yamagawa $\left(30^{\circ} \mathrm{N}\right)$, Adelaide $\left(35^{\circ} \mathrm{S}\right)$, Saskatoon $\left(52^{\circ} \mathrm{N}\right)$, and Scott Base $\left(78^{\circ} \mathrm{S}\right)$, etc. These radars contribute to studies of planetary, tidal, and gravity waves as well as mean winds in the MLT region by a number of researchers (e.g., Vincent and Lesicar, 1991; Brown, 1992; Manson and Meek, 1993; Igarashi et al., 1996).

There has been a controversy on the MF SA wind measurement at altitudes higher than $85-90 \mathrm{~km}$, which was initiated by Hines et al. (1993) because their results have shown variable agreement between the Arecibo incoherent scatter radar and collocated HF/SA radar at those altitudes. However Hines' (1993) interpretation of the observed results is also controversial. There have been works addressing this question (e.g., Reid, 1996). Independent works on the MF radar wind estimation suggested that MF SA systems possibly underestimate the wind velocity at altitudes $>85-90 \mathrm{~km}$ (Cervena and Reid, 1995; Burrage et al., 1996). Modification of the MF radar system resulted in improved agreement of MF and meteor winds (Vincent et al., 1994). Because our results of the Yamagawa MF radar at the time of the foil chaff experiment provide only altitude coverage below $88 \mathrm{~km}$, we will not give a substantial discussion on this point.

In this paper, we present experimental results of wind velocities observed with the chaff (foil chaff) experiments at 1200 and 1315 UT on 14 January 1997 from the Kagoshima Space Center (KSC), Uchinoura $\left(31^{\circ} \mathrm{N}, 131^{\circ} \mathrm{E}\right)$, Japan, and 

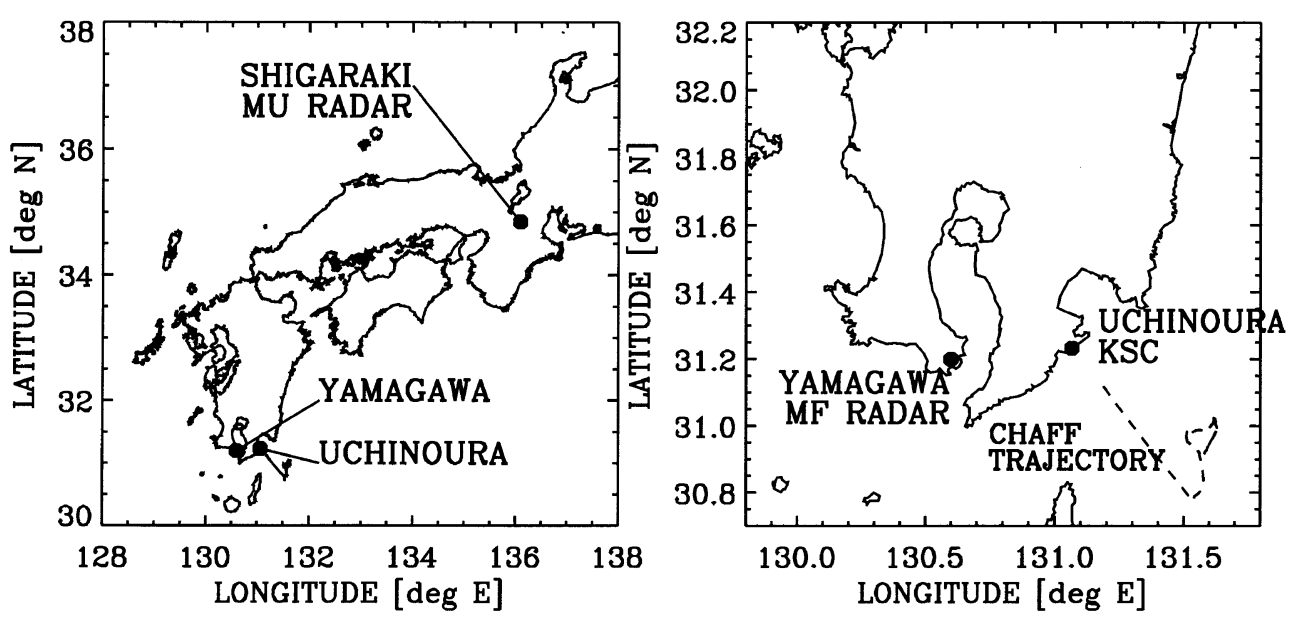

Fig. 1. Locations of the experimental sites, the rocket range, Kagoshima Space Center (KSC) at Uchinoura, Yamagawa MF radar, and the MU radar at Shigaraki. Note that the trajectory of a foil chaff cloud launched at 1315 UT on 14 January 1997 is also plotted (dashed line).

they are compared with simultaneous ground-based observations, obtained by means of the CRL Yamagawa MF radar $\left(31^{\circ} \mathrm{N}, 131^{\circ} \mathrm{E}\right)$ about $50 \mathrm{~km}$ west of $\mathrm{KSC}$, and the MU radar $\left(35^{\circ} \mathrm{N}, 136^{\circ} \mathrm{E}\right)$ about $600 \mathrm{~km}$ north-east of KSC using a meteor wind measurement mode (MU/meteor experiment). Outside the European region, these foil chaff experiments are the first to be conducted successfully. Chaff wind velocity is compared with the MF radar wind velocity to determine how much they agree in the common observed height region, and they are compared/contrasted with MU/meteor winds to describe horizontal extension of a wave structure observed at the two remote sites. Further analysis of fluctuations of chaff wind velocity and chaff descent speed for vertical velocity estimation are presented.

The outline of this paper is as follows: in Section 2, we describe the experiments and data reduction related to the techniques; in Section 3, the observed results, their comparisons, and some more details of the chaff wind analysis are presented; in Section 4, discussions are given; in Section 5, the results are summarized.

\section{Experiments and Data Reduction}

For this study, we conducted two foil chaff experiments at 1200 and 1315 UT (2100 and 2215 local time) on 14 January 1997, by using two Viper III-A micro-meteorological rockets launched from $\mathrm{KSC}$, Uchinoura $\left(31^{\circ} \mathrm{N}, 131^{\circ} \mathrm{E}\right)$. Simultaneous observations of MLT winds were obtained with the MU radar $\left(35^{\circ} \mathrm{N}, 136^{\circ} \mathrm{E} ; \sim 600 \mathrm{~km}\right.$ east of the chaff release location), and the Yamagawa MF $\operatorname{radar}\left(31^{\circ} \mathrm{N}, 131^{\circ} \mathrm{E} ; \sim 100 \mathrm{~km}\right.$ west). The locations of the sites are shown in Fig. 1, together with a chaff trajectory projection at $1315 \mathrm{UT}$.

The MU radar (46.5 MHz), which operated for 10-20 January 1997 in a meteor mode, observed meteor winds at an altitude range of $\sim 75-100 \mathrm{~km}$, with time and vertical resolutions of $30 \mathrm{~min}$ and $1 \mathrm{~km}$, respectively. The radar wave transmitted from the MU radar is reflected by an ionized meteor trail, which is thought to drift with ambient wind motion. From each meteor echo, the location of the trail and line-of-sight velocity from the Doppler shift are determined with an interferometer using four Yagi-antenna elements of the antenna array. A number of collected velocity values are averaged in a time-height bin of $30 \mathrm{~min}$ and $1 \mathrm{~km}$, respectively, in order to provide a wind velocity vector averaged in each bin. The meteor wind technique, configuration, and other details for the MU radar are described elsewhere (e.g., Nakamura et al., 1991; 1997). Uncertainty of the resultant wind velocity includes both estimation error and geophysical variability within the temporal and spatial sampling volume. Hasebe et al. (1997) calculated the precision of the MU radar meteor winds through comparison with results of HRDI onboard the UARS satellite and the Jakarta meteor radar, the error except for the geophysical noise being estimated to be $\sim 6 \mathrm{~m} / \mathrm{s}$.

The Yamagawa MF radar (1.995 MHz), which has operated continuously since August 1994, observes horizontal wind velocities at $60-98 \mathrm{~km}$ during the daytime and 80 $98 \mathrm{~km}$ at night (Igarashi et al., 1996). From the ionospheric $\mathrm{D}$ region, the partial reflection echo of the radar wave is projected to the ground, and motion of the resultant diffraction pattern is detected by three spaced antennas. By processing the received signals using the full correlation analysis (e.g., Briggs, 1984), the horizontal wind velocity is calculated. The Yamagawa system has time and vertical resolutions of 2 min and $\sim 7 \mathrm{~km}$, respectively. Although MF radars typically operate with the vertical resolution of $\sim 3-4 \mathrm{~km}$, this radar caused interference with other radio communication nearby the Yamagawa observatory. Consequently the bandwidth was limited and the vertical resolution reduced. The velocity estimation error is of the order of $\sim 2 \mathrm{~m} / \mathrm{s}$ (Meek et al., 1985), but we should note that this value was estimated solely through noise floor level of wind velocity frequency spectra, without argument of geophysical variability and instrumental error involving intercomparison with other techniques like the argument of Hasebe et al. (1997).

The foil chaff technique, developed by H.-U. Widdel of Max-Planck Institut für Aeronomie (e.g., Widdel, 1987), was successfully adapted to observe wind velocity profiles in the mesosphere and lower thermosphere by using small strips of thin metalized plastic film (e.g., Widdel, 1990). The conven- 


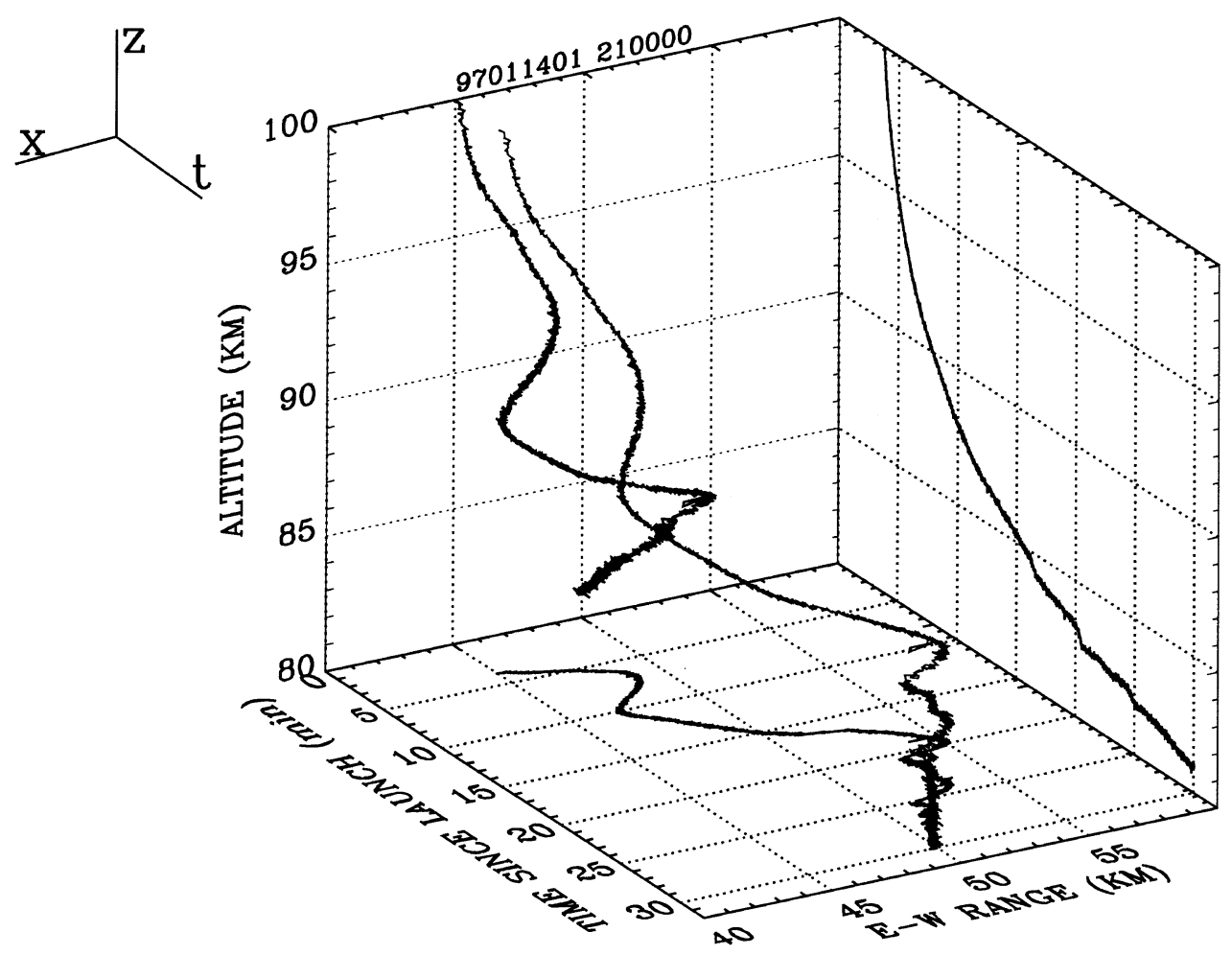

Fig. 2. Foil chaff locations determined by the ground-based tracking radar for the 1200 UT experiment. In this quasi-three-dimensional plot, the axes represent height $(z)$, time $(t)$, and east-west location $(x)$, as indicated in the small axis.

tional "needle" chaff (slender metalized cylinders), which were used during the 1950's and 1960's, did not provide optimal flight behavior for wind profiling (Widdel, 1991).

The chaff flight behavior depends on the mass-to-area ratio $R$, where $R$ is the weight of the used film per unit area. Experiments with different $R$ values are suitable for observations in different height regions. Previous experiments (Widdel, $1990)$ suggest that a foil with a thickness of $1 \mu \mathrm{m}(R=1.7$ $\mathrm{g} \mathrm{m}^{-2}$ ) is best for altitudes between 80 to $100 \mathrm{~km}$. Each chaff element used for our experiment was $25 \mathrm{~mm}$ long and $5 \mathrm{~mm}$ wide. This length is approximately one half-wavelength of the radio wave of the $\mathrm{C}$-band tracking radar and it maximizes the effective radar cross section $\sigma$. Each foil element acts as an electric dipole. The number of the foil chaff elements used for one launching can be estimated as $N=\sigma_{\text {total }} / C \sigma$, where $\sigma_{\text {total }}$ is the minimum target cross section detected by the radar when the range to the target is $110 \mathrm{~km}$, and $C$ is a factor for the actual (rotating) chaff cross section which is smaller than the ideal value (Widdel, private communication, 1995). It takes typical values of $1 / 2-1 / 6$ as a result. Calculation of $N$ suggested that several thousands of chaff elements are necessary, and 6000 strips were mounted on a rocket payload.

The foil strips mounted on the rocket were ejected at an altitude of about $110 \mathrm{~km}$ to form a chaff "cloud", which advected with the ambient wind motions during its descent. The range as well as azimuthal and elevation angles of this chaff cloud were determined by the tracking radar every 0.1 sec. After averaging the tracking data for $0.5 \mathrm{~s}$, the chaff location was calculated in the Cartesian coordinate system, and then was averaged over each $300 \mathrm{~m}$ interval. Subsequent temporal differentiation of the locations determined the descent speed and horizontal velocities. After the 15-30 min flight at altitudes from $\sim 100$ down to $\sim 80 \mathrm{~km}$, the chaff cloud tends to extend horizontally in a carpet-like form. The radar echo disappears when the chaff cloud eventually breaks up (Widdel, 1990). The height of the breaking up seems to depend on local turbulence or wave strength, resulting in an observable height range that varies roughly from 5 to $20 \mathrm{~km}$ (e.g., Widdel and von Zahn, 1990).

The height resolution of observed wind profiles has been previously reported to be $10^{1} \sim 10^{2}$ meters (Wu and Widdel, 1989). The "range constant" $h$ is an indicator of the vertical extent necessary for a chaff cloud to follow the ambient wind motion during its descent (Hyson, 1968; Widdel, 1987). For chaff elements that have a thickness of $1 \mu \mathrm{m}$, typical $h$ values at 85,90 , and $98 \mathrm{~km}$ are calculated to be $\sim 5,22$, and $500 \mathrm{~m}$, respectively. The tracking radar has the beam width of $1^{\circ}$ and the pulse width of $1 \mu \mathrm{s}$, which means that the spatial beam extent perpendicular to the beam direction is $\sim 1.6 \mathrm{~km}$ and the range depth is $\sim 0.15 \mathrm{~km}$. Assuming that the chaff cloud is spherical with a diameter of at least several hundreds of meters (Widdel, 1987), the radar sampling volume includes shell-like thin part of the cloud in which the centroid of the chaff cloud backscatter is detected. The radar tracking precision for azimuth and elevation determinations is $<0.01^{\circ}$ (beam width of $\sim 20 \mathrm{~m}$ at the $100 \mathrm{~km}$ range), and $<10 \mathrm{me}-$ ters for range. The ground-based tracking radar might be looking around the cloud dimension, so the spatial resolution may be expected to be of the order of the cloud size. In 

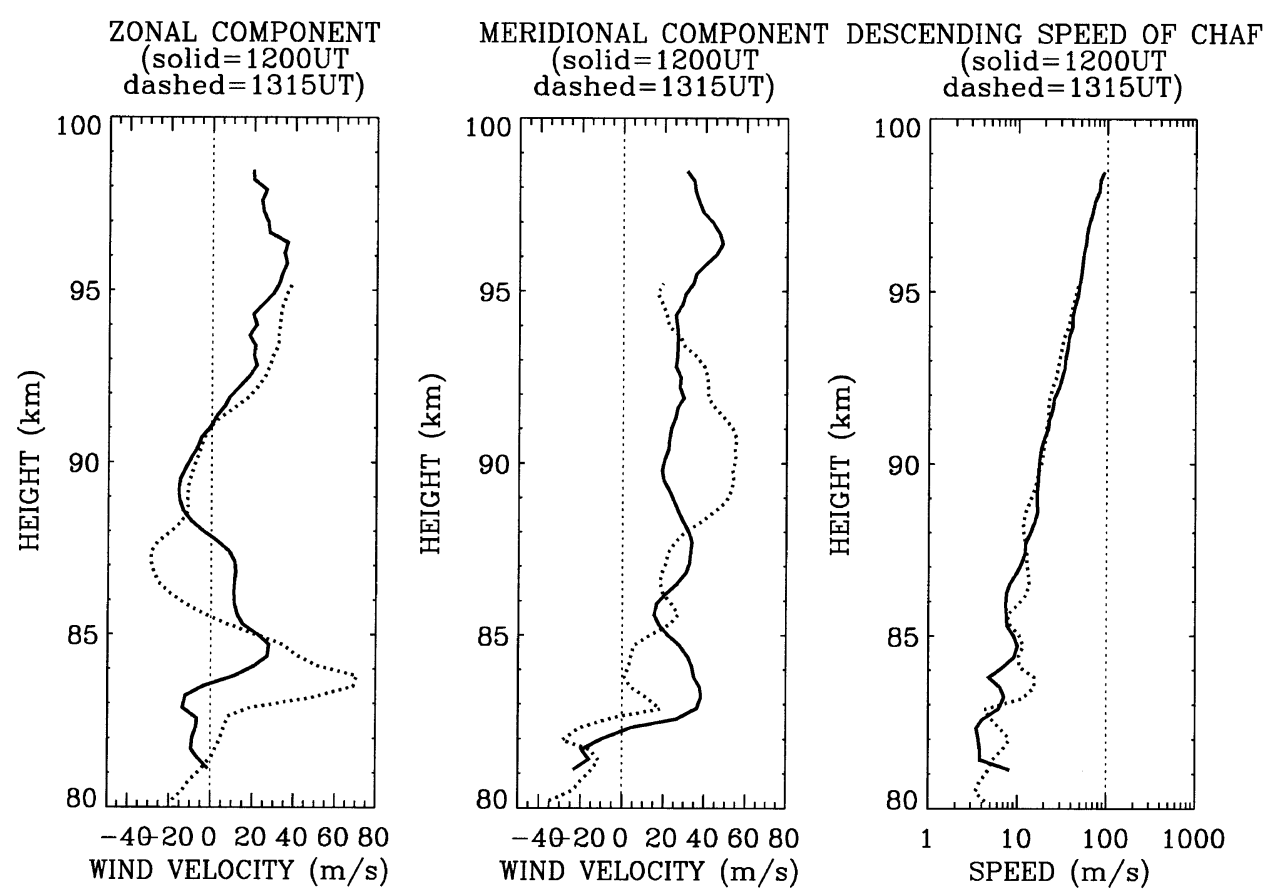

Fig. 3. Height profiles of zonal (left) and meridional (center) wind velocity and descent speed (right) obtained from the foil chaff experiments at $1200 \mathrm{UT}$ (solid) and 1315 UT (dotted) on 14 January 1997. Positive values for zonal and meridional components represent eastward and northward wind velocity, respectively. The vertical dotted line in the right panel indicates $100 \mathrm{~m} / \mathrm{s}$.

this study, first of all, we smoothed height profiles of wind velocity to achieve the height resolution of $\sim 1 \mathrm{~km}$. Even so, this resolution is better than many falling sensor techniques such as passive sphere. The passive spheres have descent speeds of $\sim 500 \mathrm{~m} / \mathrm{s}$ or more at $80-100 \mathrm{~km}$, in excess of the speed of sound, where the height resolution of wind profiles is $>8 \mathrm{~km}$ (Murayama et al., 1992a). Chaff descent speeds of $\sim 10-100 \mathrm{~m} / \mathrm{s}$ at the same heights are very much lower.

Error of horizontal location of a cloud is crucial in determining wind velocity. But, even if a very large tracking error of, e.g., $1 \mathrm{~km}$ is assumed, the horizontal velocity error is estimated to be $\sim 0.03,0.7$, and $8 \mathrm{~m} / \mathrm{s}$ at the height of 80 , 90, and $98 \mathrm{~km}$, respectively. However, sometimes careful interpretation of the chaff velocity is needed, as discussed below.

Figure 2 shows a sample of raw data of the tracked chaff location for the launch at $12 \mathrm{UT}$. During the chaff cloud descent, the tracked cloud location followed the line which is plotted as a function of height $(z)$, time $(t)$ and east-west location $(x)$. Its projection to a $z$ - $t$ plane (right hand side) shows a roughly monotonous descent of the chaff with time whose speed is approximately inversely proportional to the air density. Note that the chaff descent shows three stepwise parts at $\sim 17,20$, and 25 min since the launch, which may reflect vertical motions of ambient air. Another projection to the $x-z$ plane shows the horizontal advection of the chaff cloud during its descent as a function of $z$. The $x-t$ plane projection on the bottom shows horizontal cloud drift, which enables us to estimate the horizontal wind velocity from the temporal differentiation of this curve.

\section{Observed Results}

\subsection{Foil chaff observation}

According to the procedure described in Section 2, wind velocity profiles were calculated for the two observations by rocket launches at 1200 and 1315 UT, and are shown in Fig. 3. The zonal component demonstrates predominant eastward winds at altitudes of $93-98 \mathrm{~km}$ and tends to fluctuate at $80-93 \mathrm{~km}$, with amplitudes of $20-40 \mathrm{~m} / \mathrm{s}$. In particular the fluctuation of the 1315 UT profile is very large and the eastward wind peak value at $\sim 83.5 \mathrm{~km}$ is in excess of $70 \mathrm{~m} / \mathrm{s}$ despite of the relatively small vertical scale of the structure of $\sim 2-3 \mathrm{~km}$. Except for this significant peak, both profiles at an interval of 1 hour 15 min show different wind velocity fluctuations but similar dominant vertical scales of several to ten kilometers. The fluctuating component tends to move downward with time, implying systematic wave motions, as found, e.g., from wind velocity peaks at 89 and $87 \mathrm{~km}$ for the profiles at $1200 \mathrm{UT}$ and at 84.5 and $83.5 \mathrm{~km}$ for the profiles at 1315 UT. Such downward motions inferring gravity waves in wind profiles have been confirmed at lower heights of 30$60 \mathrm{~km}$ from previous rocket observations (Murayama et al., 1992b). The meridional component tends to predominantly show a northward wind velocity at $83-98 \mathrm{~km}$, and shows southward winds below $82 \mathrm{~km}$. Dominant fluctuations in correspondence with those of the zonal component are also found.

The observed descent speed for both profiles decreases approximately in a monotonous manner from 100 to $10 \mathrm{~m} / \mathrm{s}$ with height decreasing from 98 to $85 \mathrm{~km}$, and significant fluctuations seem to superpose on the profiles especially below $85 \mathrm{~km}$ with amplitudes of a few to $10 \mathrm{~m} / \mathrm{s}$, where the chaff descent speed values are $\sim 4-10 \mathrm{~m} / \mathrm{s}$. Note that the large 

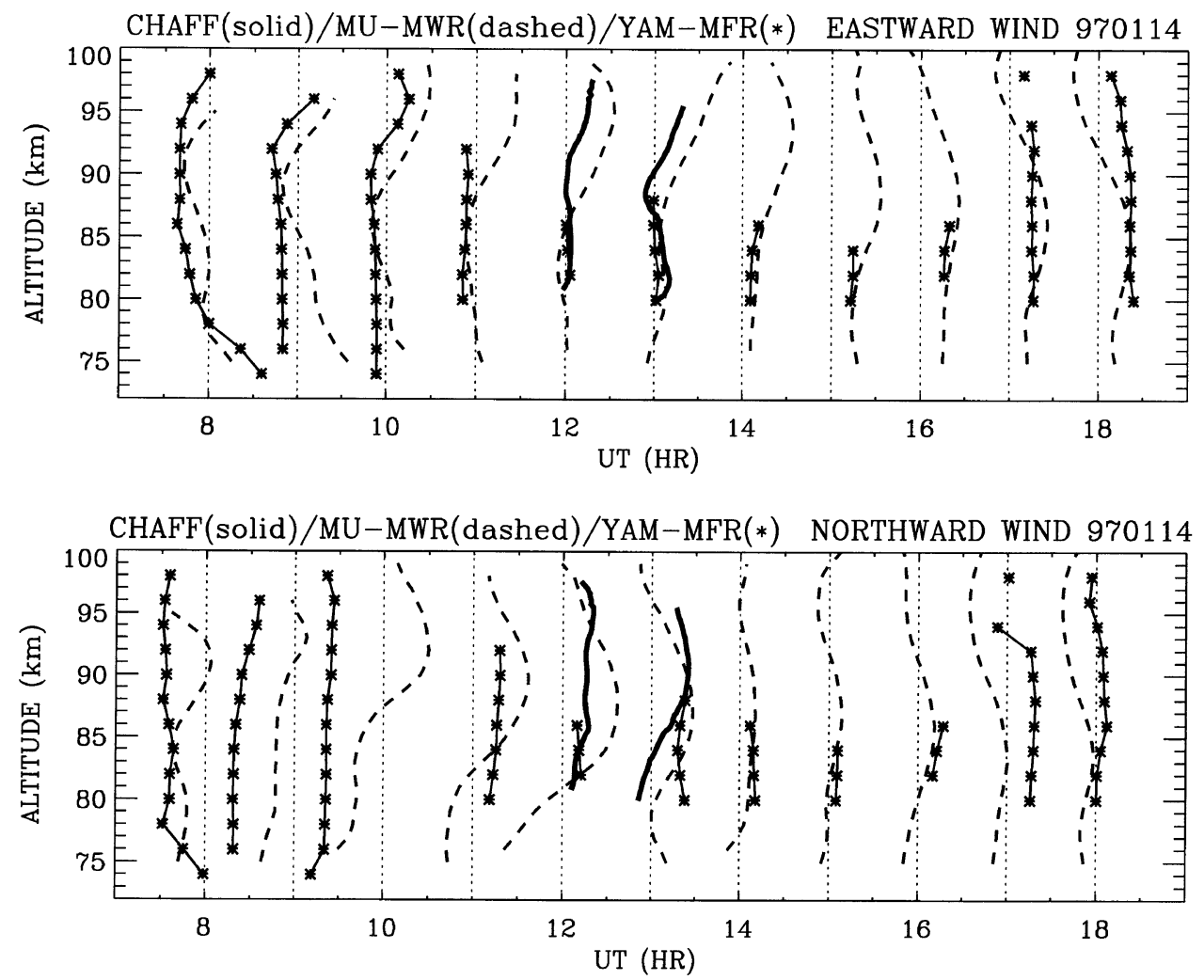

Fig. 4. Vertical profiles of zonal (top) and meridional (bottom) wind velocity observed with the foil chaff (solid), the MU radar (dashed), and Yamagawa MF radar (asterisk). The profiles are shifted by $100 \mathrm{~m} / \mathrm{s}$; so for the horizontal scale $30 \mathrm{~min}$ (minimum tick interval) represents $50 \mathrm{~m} / \mathrm{s}$. The wind velocities by the radars are hourly mean profiles, and a 7-km low-pass filter was applied to all data.

downward motions of the 1315 UT profile with velocity of $\sim 15 \mathrm{~m} / \mathrm{s}$ at $83.5 \mathrm{~km}$ coincides with the very large eastward speed at the same altitude of the 1315 UT profile.

\subsection{Smoothed wind velocity profiles and comparisons}

In this section, observed wind velocities from the two chaff experiments are compared with horizontal winds observed by the Yamagawa MF radar (hereafter MFR) and the MU radar (MUR), as presented in Fig. 4. In order to compare these data, 7-km smoothing are applied to all the profiles, since this corresponds to the MFR vertical resolution. The radar results are hourly mean values. As a result of the smoothing, the fluctuations with vertical scales of the order of kilometers in the chaff winds disappeared. Only larger scale structures can be seen significantly, which are expected to be as the results of the radar tracking of the bulk motion velocity of the chaff cloud which should advect with the background winds after all for the long time and large spatial scale. For MFR observation around this rocket experiment period, in the night condition, a large portion of data was missed at altitudes $>86$ and $>88 \mathrm{~km}$ for 1200 and 1315 UT chaff experiments, respectively, probably because of external radio interference. MUR meteor observation covered a height range greater than that of the chaff experiments.

From the MUR zonal wind profiles, we can recognize an eastward peak of $50 \mathrm{~m} / \mathrm{s}$ around $95 \mathrm{~km}$ at $10 \mathrm{UT}$, and a downward motion from $95 \mathrm{~km}$ to $88 \mathrm{~km}$ at $15 \mathrm{UT}$, while for the meridional component, we can recognize a northward wind peak of $50 \mathrm{~m} / \mathrm{s}$ at $90 \mathrm{~km}$ at $10 \mathrm{UT}$ also moving downward to $\sim 85 \mathrm{~km}$ at $13 \mathrm{UT}$. The downward speed of this motion was $\sim 0.4-0.5 \mathrm{~m} / \mathrm{s}$. For finding the wave vertical scale $\lambda_{z}$, the dominant component in meridional MUR and chaff winds around 12 UT suggest $\lambda_{z} \sim 20 \mathrm{~km}$. The wave period can be estimated to be $\sim 11-14 \mathrm{hr}$. MUR and MFR horizontal velocity time series for a period of 5 days (not shown here) exhibited semidiurnal period oscillations at both MUR and MFR sites, although a much larger vertical scale was observed by MFR. So the observed $20-\mathrm{km}$ vertical wave structure might be part of the semidiurnal tide although the vertical wavelength seems too short, and otherwise, it might be a large vertical-scale gravity wave.

The MFR results also show similar wave-like profiles for a limited portion of the plots which are found at 75-98 km at $8 \mathrm{UT}$ and at altitudes higher than $85 \mathrm{~km}$ at 9 and $10 \mathrm{UT}$ for the zonal component, despite the apparent phase shifts to the MUR profiles. However, during this period of 7-18 UT, variability in vertical structures of the MFR horizontal wind velocity tends to be small (rather flat profiles), especially for the period of 9-18 UT at altitudes $<90 \mathrm{~km}$ (although it should be noted that there are the missing parts of MFR data at altitudes $>90 \mathrm{~km}$ at 11-16 UT for both zonal and meridional components). Less variability in terms of vertical profiles is also found for the MUR zonal winds at 10-16 UT and meridional winds at 8-9 and 14-18 UT, at altitudes $<85 \mathrm{~km}$.

Taking these features of the wind profiles as the background condition during the rocket launches, the chaff and MFR profiles are compared. The zonal components at 1200 

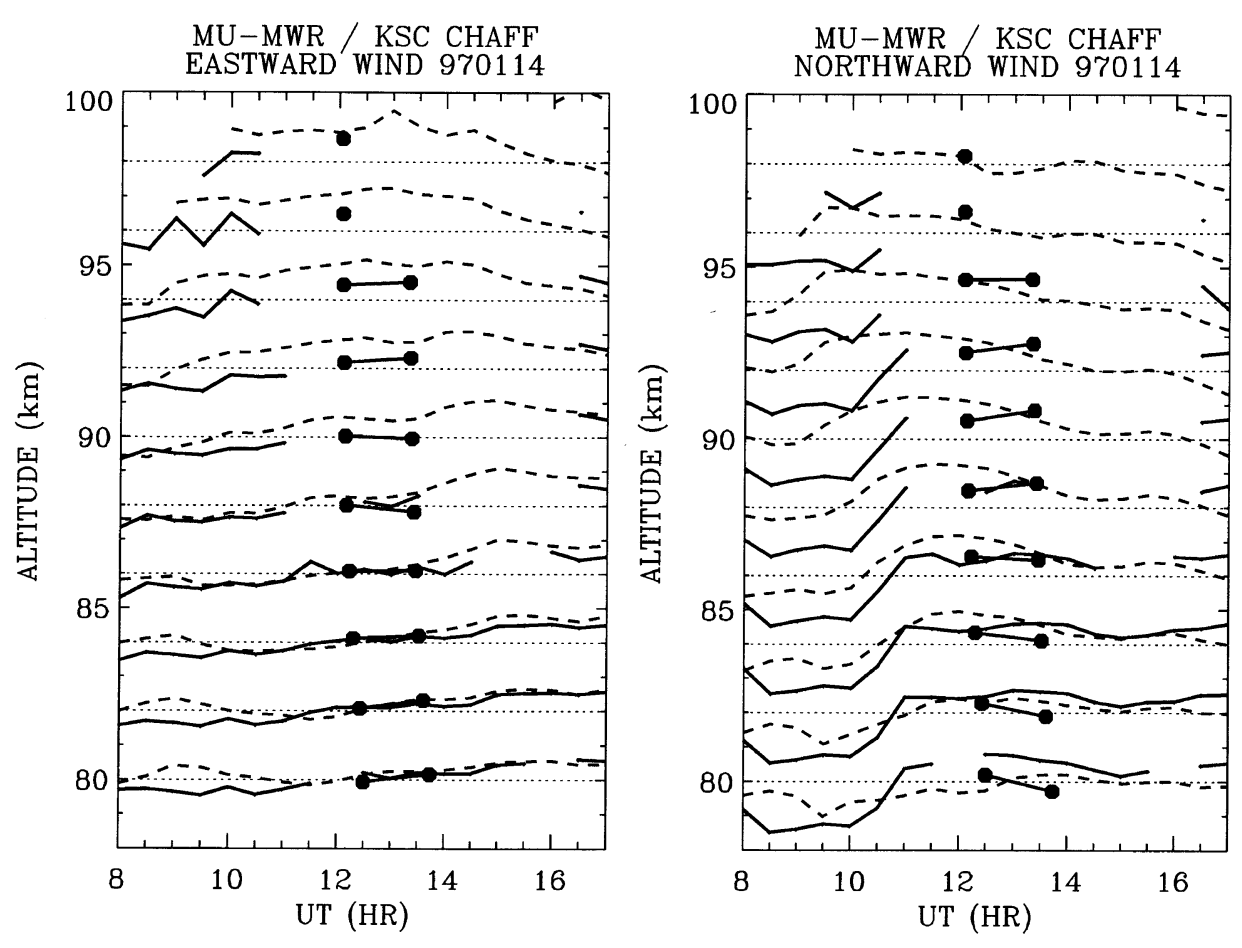

Fig. 5. Time series of chaff (filled dot), MFR (solid line), and MUR (dashed line) wind velocities for the eastward (right panel) and northward (left) component. The radar data are hourly average values. Also a 7-km low-pass filter was applied to all data. The vertical scale presents both altitude and wind velocity, where the $1 \mathrm{~km}$ interval corresponds to $50 \mathrm{~m} / \mathrm{s}$.

UT at altitudes of $82-86 \mathrm{~km}$ show weak eastward winds of $\sim 5-6 \mathrm{~m} / \mathrm{s}$ and $1-5 \mathrm{~m} / \mathrm{s}$ for chaff and MFR data, respectively, while in the second experiment at $1315 \mathrm{UT}$, the zonal wind velocity of chaff and MFR at $80-86 \mathrm{~km}$ was 0 to $20 \mathrm{~m} / \mathrm{s}$ and -1 to $5 \mathrm{~m} / \mathrm{s}$, respectively. So the zonal component exhibits good agreement between the chaff and MFR results at least in the observed height range. For the meridional component, the chaff and MFR data at $1200 \mathrm{UT}$ at $82-86 \mathrm{~km}$ showed northward winds of 5-25 m/s and 15-20 m/s, respectively, suggesting that these profiles also agree reasonably. At 1315 UT, agreement of chaff and MFR value of $\sim 40 \mathrm{~m} / \mathrm{s}$ at $88 \mathrm{~km}$ are recognized. At lower heights of $80-86 \mathrm{~km}$ chaff velocities were -13 to $22 \mathrm{~m} / \mathrm{s}$ and the MFR velocities were 30 to $40 \mathrm{~m} / \mathrm{s}$, showing that their difference increases with altitude decreasing, up to $53 \mathrm{~m} / \mathrm{s}$ at $80 \mathrm{~km}$. As a result, the zonal wind profiles of chaff and MFR show a reasonable agreement for both chaff experiments at $80-88 \mathrm{~km}$, and the meridional winds agree at $1200 \mathrm{UT}$ at $82-86 \mathrm{~km}$. But a larger difference at 1315 UT was found $(53 \mathrm{~m} / \mathrm{s}$ at the lowest height of $80 \mathrm{~km}$ ).

The MUR results are not necessarily in agreement with the chaff or MFR data, and yet that could be due to natural variability when there is significant gravity wave activity or strong gradient of the mean wind (or tidal structure). Except for the meridional component at $1200 \mathrm{UT}$, the shapes of MUR wind profiles mainly at $>85 \mathrm{~km}$ at $12-13$ UT are similar to the corresponding chaff profiles and those MUR and chaff profiles seemed to correlate with apparent vertical phase shift by $\sim 4-5 \mathrm{~km}$. This similarity implies that the phase correlation might be a manifestation of a systematic wind structure with a horizontal scale $>600 \mathrm{~km}$ like a large horizontal scale gravity wave. For the zonal component in the altitude region below $88 \mathrm{~km}$, the chaff, MFR, and MUR data tend to show rather similar values, although the meridional component shows larger differences between the chaff, MFR, and MUR experiments.

Figure 5 again shows the comparison of chaff, MFR, and MUR data in time-series presentation. For the zonal component, the agreement between chaff and MFR winds is fairly well below $86 \mathrm{~km}$, with regard to the absolute values as well as temporal trends of the both measurements. For the meridional component, the 1200 UT chaff experiment provided good agreement with MFR, although the difference of chaff and MFR at 1315 UT is again significant. This figure also shows that the MFR and MUR wind time series are relatively similar to each other for the zonal component, while the meridional component shows more locality or variability, and possible latitudinal or geographical difference in the wind fields.

\subsection{Wind velocity fluctuations observed with chaff}

By extracting fine wind velocity fluctuations from the wind profiles in Fig. 3, vertical profiles and hodograph of the fluctuating component are shown in Fig. 6, which was obtained by the numerical filter with a pass band of $1-3 \mathrm{~km}$. This fluctuating component was superposed on the wind field just below the eastward wind peak at $83.5 \mathrm{~km}$ of the total component. The hodograph clearly demonstrates an ellipse-like motion although only $\sim 2 / 3$ portion of the whole ellipse is seen. The wind vector rotates clockwise with altitude increasing, so if we interpret this motion as a gravity wave, the wave group velocity seemed upward. The vertical wavelength $\lambda_{z}$ is estimated $\sim 2 \mathrm{~km}$. 

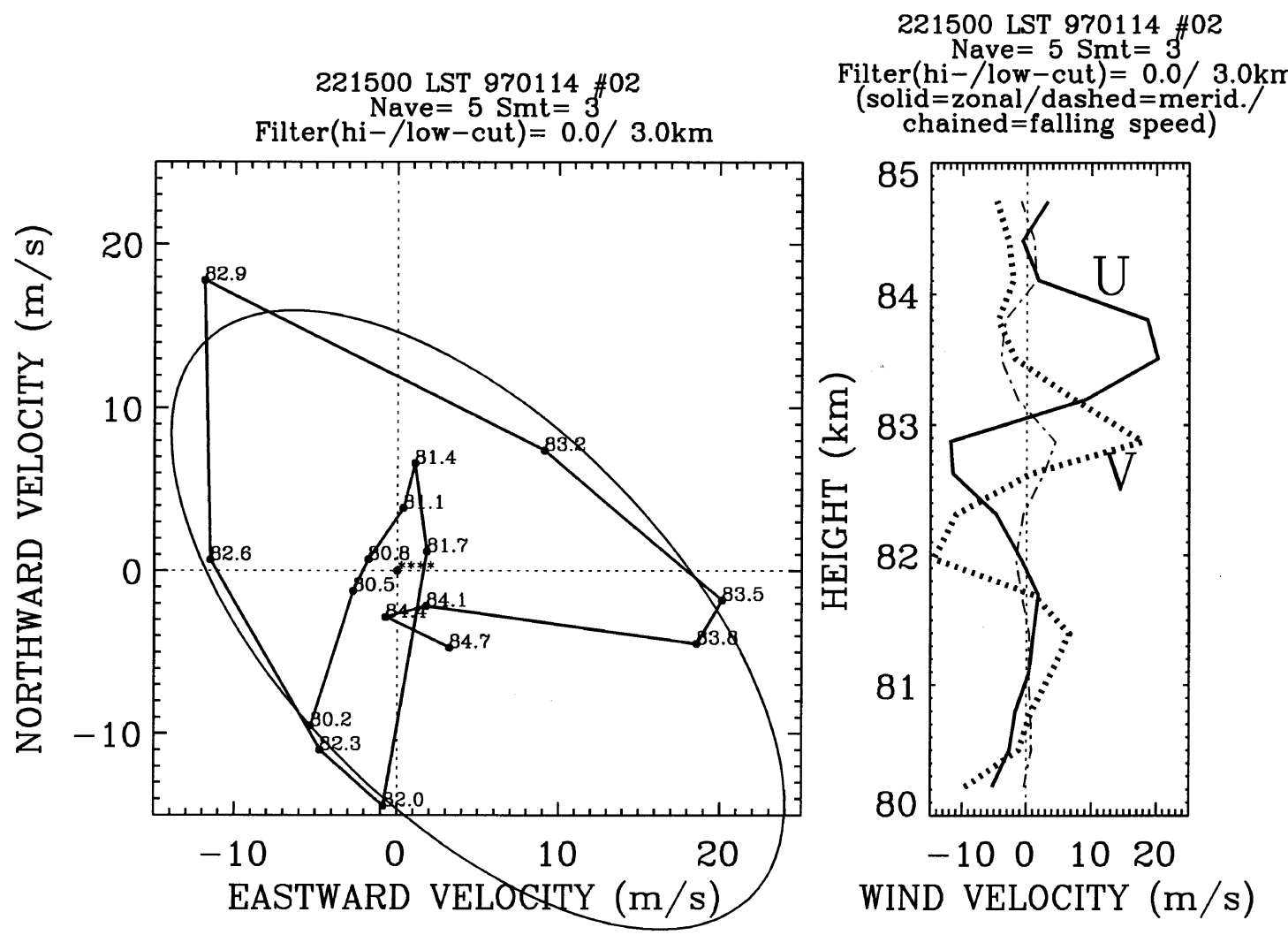

Fig. 6. (left) Hodograph and (right) height profiles of wind velocities observed by chaff at 1315 UT, after band-pass filtering of $1-3 \mathrm{~km}$ vertical scales. In the right panel, the solid and dashed lines represent zonal and meridional winds, respectively, and the chained line indicates the negative descent speed of the chaff cloud, the positive value indicating an upward motion.

Regarding the chaff descent speed, $V_{\mathrm{D}}$, Widdel (1987) and Widdel et al. (1994) suggested that the descent velocity includes the equilibrium descent speed $V_{\text {Deq }}$ as a function of background air density and temperature and also true vertical wind motions, $w$. Widdel used background density profiles observed by falling spheres to calculate $V_{\text {Deq }}$ profiles, while we have no sphere data for the chaff data analysis. If smoothed chaff descent speed, which was removed by the above numerical filtering, is assumed to represent the $V_{\text {Deq }}$ profile, we can take $V_{\mathrm{D}}^{\prime}=-w^{\prime}$, where prime (') means the fluctuating component. When significant density changes occur, the resultant $V_{\text {Deq }}$ variation will cause the change of $V_{\mathrm{D}}^{\prime}$. In this case, true $V_{\text {Deq }}$ values need to be observed for estimating $w^{\prime}$. However, possible density variations of $\sim 10 \%$ can induce the $w^{\prime}$ change of only $0.3 \mathrm{~m} / \mathrm{s}$ for $V_{\text {Deq }} \sim 10 \mathrm{~m} / \mathrm{s}$ at heights shown in Fig. 6. Assuming $V_{\mathrm{D}}^{\prime} \sim-w^{\prime}$, the vertical velocity fluctuations are fairly consistent with the zonal and meridional wind fluctuations qualitatively in Fig. 6, in terms of the gravity wave interpretation.

The hodograph ellipse and the vertical velocity suggest that this wave propagated in the north-west direction, and that the measurement of the major and minor axis lengths of the ellipse, $u^{\prime}$ and $v^{\prime}$ of $\sim 24$ and $12 \mathrm{~m} / \mathrm{s}$, respectively, results in wave parameters such as the intrinsic period of $\sim 12 \mathrm{hrs}$, horizontal wavelength of $288 \mathrm{~km}$, and thus a horizontal phase speed, $c$, of $6.7 \mathrm{~m} / \mathrm{s}$. Wave-induced vertical wind velocity expected from the wave amplitudes and the wave period can be estimated, which resulted in $\sim 0.2 \mathrm{~m} / \mathrm{s}$, being smaller by
Table 1. Gravity wave parameters obtained from the hodograph ellipse of chaff wind velocity fluctuations at 1315 UT on 14 January 1997.

\begin{tabular}{ll}
\hline Parameter & Value \\
\hline Amplitude & \\
Major axis of the ellipse $\left(u^{\prime}\right)$ & $24 \mathrm{~m} / \mathrm{s}$ \\
Minor axis $\left(v^{\prime}\right)$ & $12 \mathrm{~m} / \mathrm{s}$ \\
Expected vertical component & $0.2 \mathrm{~m} / \mathrm{s}$ \\
Chaff descent speed fluctuation $\left(V_{\mathrm{D}}^{\prime}\right)$ & $5 \mathrm{~m} / \mathrm{s}$ \\
Vertical wavelength & $2 \mathrm{~km}$ \\
Horizontal wavelength & $288 \mathrm{~km}$ \\
Intrinsic period & $12 \mathrm{hr}$ \\
Horizontal phase speed & $6.7 \mathrm{~m} / \mathrm{s}$ \\
\hline
\end{tabular}

a factor of 25 than the observed value of $\sim 5 \mathrm{~m} / \mathrm{s}$. The wave parameters are summarized in Table 1.

Even with this qualitative consistency with the gravity wave interpretation, the total component of the eastward wind velocity at 1315 UT in Fig. 3 still seems unusual. We attempted to examine the statistical aspects of the wind fields by calculating the vertical wavenumber spectra. The results in Fig. 7 indicate that the spectral density at vertical scales $>1 \mathrm{~km}$ are reasonably in agreement with or are smaller than 

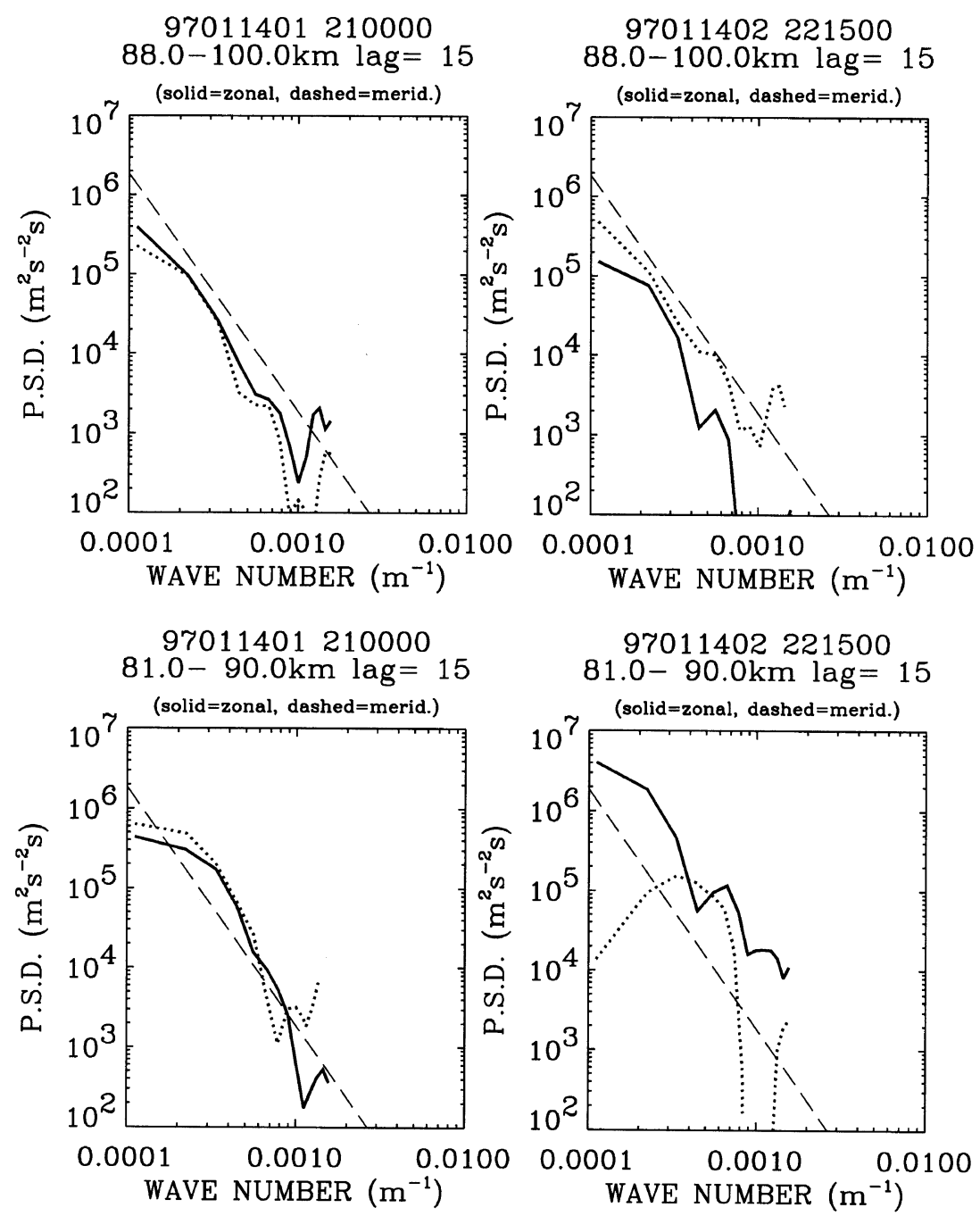

Fig. 7. Vertical wavenumber spectra of zonal (solid line) and meridional (dotted line) wind velocities observed with the chaff technique. The top and bottom panels present data at the height range of 88-100 km and 81-90 km, respectively, at 1200 UT (left two panels), and $1315 \mathrm{UT}$ (right two panels). The long dashed line indicates the spectral model of saturated gravity waves derived from the linear saturation theory, $F_{u}^{s}(m)=N^{2} / 6 m^{3}$.

the model values of saturated gravity wave spectrum (Smith et al., 1987), except for the spectra observed at 1315 UT in the $81-90 \mathrm{~km}$ altitude region which showed larger amplitudes than the saturated spectrum by factors less than 10 . Note that the model saturated spectrum is a result of statistical superposition of many waves, and for a monochromatic gravity wave the saturation limit becomes larger by a factor of 3. The large spectral amplitude values in Fig. 7 might be due to a very strong monochromatic wave.

\section{Discussion}

Regarding the comparison between the chaff and MFR horizontal winds, Figs. 4 and 5 demonstrated that during the two rocket experiments at 1200 and 1315 UT on 14 January 1997, the zonal component of the chaff and MFR winds generally agreed well in terms of height structure and temporal trends at the altitudes of $80-88 \mathrm{~km}$. For the meridional component, the chaff winds at 1200 UT were in reasonable agreement with the MFR winds. The only exceptions are the chaff and MFR data at 1315 UT in the altitude region of $80-84 \mathrm{~km}$, which were different by $\sim 5-50 \mathrm{~m} / \mathrm{s}$ and the discrepancy increased as the altitude decreased.

The argument of wind measurement validity of the MF/HF radar is mainly on the lower thermospheric wind data at altitudes $>85-90 \mathrm{~km}$. The observed general agreement between chaff and MFR winds for both zonal and meridional components in the altitude range observed by MFR of $80-88 \mathrm{~km}$ supports that the MFR measurement provides true wind velocity in this height range. Although there was an exceptional discrepancy for the meridional components of MFR winds larger than chaff winds at 1315 UT, this may not be attributed to MF radar measurement but maybe due to local disturbance. This discrepancy was at mesospheric heights of 80-84 km, and the validity argument does not include mesospheric measurements. In addition, previous arguments on the MF radar wind measurement suggested an underestimation at the thermospheric heights. (e.g., Burrage et al., 1996; Igarashi et al., 1996; Reid, 1996; Holdsworth and Reid, 1997).

When we again see the chaff wind profiles without 7-km smoothing in Fig. 3, the very large eastward wind velocity at $\sim 83.5 \mathrm{~km}$ is recognized. This kind of high horizontal wind speed has also been reported from previous foil chaff exper- 
iments (Widdel, 1991). Widdel (1991) showed very large northward wind velocity $>100 \mathrm{~m} / \mathrm{s}$ with a vertical scale of several kilometers, which was simultaneously detected by two tracking radars that traced one chaff cloud from the different azimuth angles. This large velocity was associated with larger downward velocity. Plausible reasons for this large velocity may be due to a particular atmospheric phenomenon or maybe due to an apparent velocity of a strong radar echoing point that might drift in a significantly spread chaff cloud.

Widdel suggested that this phenomenon might be attributed to a short-lived transient disturbance that is accompanied by a large local pressure decrease, which could cause the sudden chaff falling in a local region of the low air density. Actually the descent velocity profile at 1315 UT in Fig. 3 showed that the downward velocity peak as large as $15 \mathrm{~m} / \mathrm{s}$ at $\sim 83.5 \mathrm{~km}$ coincided with the eastward velocity peak. Similar pressure decrease events, which are thought to be accompanied by phenomena called "bore", are often observed in the troposphere (e.g., Christie et al., 1978; Mahapatra et al., 1991). Some of the tropospheric pressure decrease events are observed for only a short time (a few hundreds of seconds). Radar measurements of such an event may be difficult since the radars need a few minutes or more to integrate the data, and only techniques that have a short integration time such as the foil chaff could observe it. However, the chaff vertical velocity fluctuations as large as $5 \mathrm{~m} / \mathrm{s}$ is $30 \%$ of the total vertical velocity of $15 \mathrm{~m} / \mathrm{s}$, and the implied local air density decrease of $\sim 60 \%$ does not seem usual.

A recent work by Dewan and Picard (1998), motivated by an airglow observation by Taylor et al. (1995) that demonstrates a mesospheric traveling front and a following wave train, suggests that an undular bore might occur in the mesosphere. Dewan and Picard (1998), referring to previous studies on the water surface bore and tropospheric bore events, extended the surface bore theory to the internal bore case. Dewan and Picard (1998) suggest that, in the case of a strong mesospheric temperature inversion layer, a vertical velocity of $7-15 \mathrm{~m} / \mathrm{s}$ both upward and downward associated with the undulation seems possible by using bore and wave parameters observed by Taylor et al. (1995). Also a bore passage can associate an additional horizontal flow inside a channel around the inversion layer height. This flow speed could be of the order of $20 \mathrm{~m} / \mathrm{s}$ using the same bore parameters. From our observation, amplitude of the chaff vertical velocity fluctuations of $5 \mathrm{~m} / \mathrm{s}$ is the same order of the value predicted from the internal bore theory, but the large chaff velocity of $70 \mathrm{~m} / \mathrm{s}$ at $83.5 \mathrm{~km}$ is still larger than this flow speed of $20 \mathrm{~m} / \mathrm{s}$. An increase of zonal wind peak speed at 83-84 km from the first to the second chaff experiment is by $42 \mathrm{~m} / \mathrm{s}$, which is still larger but of the same order of the theoretical value. These suggestions from the new internal bore theory might lead to possible explanation of the chaff large horizontal and vertical velocities. Further observations of, e.g., temperature and undular bore evidence are needed to confirm this interpretation.

From another view point, we may consider the possibility that apparent velocity was observed due to the chaff flight behavior and radar tracking characteristics. The large velocity events observed by Widdel (1991) (>100 m/s) were located at an altitude of $\sim 87 \mathrm{~km}$, and our experiments $(\sim 70 \mathrm{~m} / \mathrm{s})$ were located at an altitude of $83.5 \mathrm{~km}$, where the chaff clouds might spread and become larger clouds after falling from $\sim 100 \mathrm{~km}$ down to $83-87 \mathrm{~km}$. Horizontal speeds of 100 and $70 \mathrm{~m} / \mathrm{s}$ are comparable to peak values of the middle atmosphere jet, but the jet has vertical scales of tens of kilometers.

During a regular descent of chaff at upper heights, the vertical extent of the cloud are suggested to be smaller than several hundreds of meters from the radar tracking data of Widdel (1990). However at lower heights, the chaff clouds tend to form horizontally thin structures (Widdel, 1987, 1990). For the spread cloud, we might suggest that in special occasions the radar does not only track the location of a bulk cloud but also tracks an apparent motion of a locally strong echo region (which might travel along the spread cloud with the apparent velocity). In a particular case, when the chaff descends into a locally strong shear region, the cloud shape would be deformed or modulated into an obliquely spread cloud due to different drags at different heights. Thus the apparent motion of the radar tracking point, if any, might be associated with large apparent velocities in both horizontal and vertical directions. To explain the observed large velocities at 83$84 \mathrm{~km}$ at $1315 \mathrm{UT}$, the horizontal and vertical cloud extent seem to need $\sim 2-4 \mathrm{~km}$ and $\sim 0.7-1 \mathrm{~km}$ at least.

Despite this argument of the high wind speed field, in Section 3 we have discussed the fluctuations of chaff velocity with a small vertical scale of $\sim 2 \mathrm{~km}$ which were partially superposed on the large horizontal wind velocity field as discussed above. The hodograph ellipse and chaff vertical velocity fluctuations were qualitatively consistent with the gravity wave interpretation, although the validity of the observed vertical velocity fluctuation amlitude seems controversial. We should also note that the horizontal wind amplitude $u^{\prime} \sim 24 \mathrm{~m} / \mathrm{s}$ of the wave with a vertical wavelength of $2 \mathrm{~km}$ tends to be larger than those found in previous radar studies. For instance, MU radar observation by Yamamoto et al. (1988) showed that a monochromatic gravity wave in the mesosphere with a vertical wavelength of $3 \mathrm{~km}$ had amplitude of $6 \mathrm{~m} / \mathrm{s}$. Also horizontal wind variance, $\overline{u^{\prime 2}}+\overline{v^{\prime 2}}$, with a band-pass filter of $1.5-3.5 \mathrm{~km}$ were observed with the MU radar at 65-85 km in January-March 1990 (Tsuda et al., 1992). The resulted values ranged from 2 to $100 \mathrm{~m}^{2} / \mathrm{s}^{2}$. Assuming that only a monochromatic wave contributes to each variance value, $100 \mathrm{~m}^{2} / \mathrm{s}^{2}$ leads to a mean wave amplitude of $\sim 7 \mathrm{~m} / \mathrm{s}$.

\section{Summary}

In this paper, we have shown the results of the first two foil chaff experiments outside the European region that observed wind velocity profiles in the upper mesosphere and lower thermosphere. These experiments were conducted at 1200 UT and 1315 UT on 14 January 1997 from the Kagoshima Space Center (KSC), Uchinoura $\left(31^{\circ} \mathrm{N}, 131^{\circ} \mathrm{E}\right)$, Japan. A comparison of the chaff results were made using simultaneous ground-based radar observations with the MU $\operatorname{radar}\left(35^{\circ} \mathrm{N}, 136^{\circ} \mathrm{E}\right) \sim 600 \mathrm{~km}$ north-east of KSC (using a meteor wind measurement mode), and the CRL Yamagawa $\mathrm{MF} \operatorname{radar}\left(31^{\circ} \mathrm{N}, 131^{\circ} \mathrm{E}\right) \sim 50 \mathrm{~km}$ west of KSC. Also velocity profiles and their fluctuating components of the chaff measurements are analyzed. The obtained results are sum- 
marized below.

1) Wind velocity profiles at altitudes of 81-98 and 80 $95 \mathrm{~km}$ were successfully observed with the foil chaff experiments at 1200 and 1315 UT, respectively, on 14 January 1997.

2) The zonal component of the chaff winds generally agreed well with that of MFR winds in terms of height structure and temporal trends, at the altitudes of 80 $88 \mathrm{~km}$. For the meridional component, the chaff winds at 1200 UT agreed reasonably with MFR winds, while at 1315 UT MFR winds were larger than chaff winds by $\leq 50 \mathrm{~m} / \mathrm{s}$ at $80-84 \mathrm{~km}$.

3) MUR, MFR, and chaff wind velocities showed that the wind fields were reasonably consistent with each other. MUR winds showed a dominant wave structure with a vertical scale of $\sim 20 \mathrm{~km}$ and an estimated wave period of 11-14 hr. This wave structure could also be seen in chaff and MFR data, at least in the limited height region mainly above $85-90 \mathrm{~km}$. This wave might be a large scale gravity wave.

4) The chaff eastward wind velocity profile at 1315 UT exhibited a very large wind velocity of $>70 \mathrm{~m} / \mathrm{s}$ at $\sim 83.5 \mathrm{~km}$ that coincided with the large downward velocity. The vertical wavenumber spectrum of the eastward component of this profile was somewhat larger than the saturated spectrum model values, and assuming a monochromatic wave, the difference of the spectrum and model becomes smaller by a factor of 3 .

5) Velocity fluctuations with a vertical scale of $2 \mathrm{~km}$ at 82-85 km was extracted from chaff winds and descent speeds at 1315 UT. The hodograph seemed consistent with a gravity wave interpretation. It is noteworthy that the fluctuating component of the chaff descent velocity, as a representative of vertical wind fluctuations, was also consistent with the wave feature.

The horizontal velocity amplitude of the wave, $u^{\prime} \sim 24$ $\mathrm{m} / \mathrm{s}$, was larger than results of previous radar observations. Also the amplitude of the vertical velocity fluctuations were larger by one order than that estimated from the wave-induced horizontal wind fluctuations.

It is suggested that in principle the foil chaff technique observes horizontal wind velocity and vertical wind fluctuations. The observed consistency with the wave interpretation supports the vertical velocity estimation from chaff descent first attempted by Widdel (1987) and Widdel et al. (1994). But, in a more quantitative aspect of gravity wave analysis, in this kind of special case wind velocities observed by the chaff might not reflect only actual wind fields but also some other process, candidates of which are the internal "bore", and apparent tracking motions.

Acknowledgments. The Yamagawa MF radar at the CRL Yamagawa Radio Observatory was constructed with help of Drs. R. A. Vincent and I. M. Reid, University of Adelaide, Australia. The MU radar belongs to, and is operated by the Radio Atmospheric Science Center, Kyoto University.

\section{References}

Briggs, B. H., The analysis of spaced sensor records by correlation techniques, Handbook for MAP, 13, 166-186, University of Illinois, Urbana, Illinois, U.S.A., 1984

Brown, W. O. J., MF radar interferometry, Ph.D. thesis, pp. 303, University of Canterbury, NZ, 1992.

Burrage, M. D., W. R. Skinner, D. A. Gell, P. B. Hays, A. R. Marshall, D. A. Ortland, A. H. Manson, S. J. Franke, D. C. Fritts, P. Hoffman, C. McLandress, R. Niciejewski, F. J. Schmidlin, G. G. Shepherd, W. Singer, T. Tsuda, and R. A. Vincent, Validation of mesosphere and lower thermosphere winds from the high resolution Doppler imager on UARS, J. Geophys. Res., 101, 10365-10392, 1996.

Cervena, M. A. and I. M. Reid, Comparison of simultaneous wind measurements using collocated VHF meteor radar and MF spaced antenna radar systems, Radio Sci., 30, 1245-1261, 1995.

Christie, D. R., K. J. Muirhead, and A. L. Hales, On solitary waves in the atmosphere, J. Atmos. Sci., 35, 805-825, 1978.

Dewan, E. M. and R. H. Picard, Mesospheric bores, J. Geophys. Res., 103, 6295-6305, 1998.

Hasebe, F., T. Tsuda, T. Nakamura, and M. D. Burrage, Validation of HRDI MLT wind with meteor radars, Ann. Geophysicae, 15, 1142-1157, 1997.

Hines, C. O., G. W. Adams, J. W. Brosnahan, F. T. Djuth, M. P. Sulzer, C. A. Tepley, and J. S. Van Baelen, Multi-instrument observations of mesospheric motions over Arecibo: comparisons and interpretations, $J$. Atmos. Terr. Phys., 55, 241-287, 1993.

Holdsworth, D. A. and I. M. Reid, An investigation of biases in the full correlation analysis technique, Adv. Space Res., 20(6), 1269-1272, 1997.

Hyson, P., Windfinding data from radar tracking of high altitude sensors, $Q$. J. R. Meteorol. Soc., 94, 592-597, 1968.

Igarashi, K., I. Nishimuta, Y. Murayama, T. Tsuda, T. Nakamura, and M. Tsutsumi, Comparison of wind measurements between Yamagawa MF radar and the MU radar, Geophys. Res. Lett., 23, 3341, 1996.

Mahapatra, P. R., R. J. Doviak, and D. S. Zrnić, Multisensor observation of an atmospheric undular bore, Bull. Am. Meteorol. Soc., 72, 1468-1480, 1991.

Manson, A. H. and C. E. Meek, Characteristics of gravity waves (10 min-6 hours) at Saskatoon $\left(52^{\circ} \mathrm{N}, 107^{\circ} \mathrm{W}\right)$ : Observations by the phase coherent medium frequency radar, J. Geophys. Res., 98, 20357-20367, 1993.

Meek, C. E., I. M. Reid, and A. H. Manson, Observations of mesospheric wind velocities 1 . Gravity wave horizontal scales and phase velocities determined from spaced wind observations, Radio Sci., 20, 1363-1382, 1985.

Murayama, Y., K.-I. Oyama, T. Tsuda, H. Kanzawa, T. Nakamura, M. D. Yamanaka, S. Fukao, and S. Kato, Rocketsonde Observations of the Middle Atmosphere Dynamics at Uchinoura $\left(31^{\circ} \mathrm{N}, 131^{\circ} \mathrm{E}\right)$ during DYANA Campaign. Part I: Outline of Experiments and Background Conditions, J. Geomag. Geoelectr., 44, 995-1007, 1992a.

Murayama, Y., T. Tsuda, M. Yamamoto, T. Nakamura, T. Sato, S. Kato, and S. Fukao, Dominant Vertical Scales of Gravity Waves in the Middle Atmosphere Observed with the MU Radar and Rocketsondes, J. Atmos. Terr. Phys., 54, 339-346, 1992b.

Nakamura, T., T. Tsuda, M. Tsutsumi, K. Kita, T. Uehara, S. Kato, and S. Fukao, Meteor wind observations with the MU radar, Radio Sci., 26 857-869, 1991.

Nakamura, T., T. Tsuda, S. Fukao, H. Takahashi, P. P. Batista, R. A. Buriti, M. Tsutsumi, M. Ishii, K. Igarashi, H. Fukunishi, Y. Yamada, A. Nomura T. D. Kawahara, K. Kobayashi, C. Nagasawa, M. Abo, and M. J. Taylor, Studies of the MLT regions using the MU radar and simultaneous observations with $\mathrm{OH}$ spectrometer and other optical instruments, Adv. Space Res., 19, 643-652, 1997.

Reid, I. M., On the measurement of gravity waves, tides and mean winds in the low and middle latitude mesosphere and thermosphere with MF radar, Adv. Space Res., 18, (3)131-(3)140, 1996.

Smith, S. A., D. C. Fritts, and T. E. VanZandt, Evidence for a saturated spectrum of atmospheric gravity waves, J. Atmos. Sci., 44, 1404-1410, 1987

Taylor, M. J., D. N. Turnbull, and R. P. Lowe, Spectrometric and imaging measurements of a spectacular gravity wave event observed during the ALOHA-93 campaign, Geophys. Res. Lett., 22, 2848-2852, 1995.

Tsuda, T., Y. Murayama, K.-I. Oyama, H. Kanzawa, T. Nakamura, M. D. Yamanaka, S. Fukao, and S. Kato, Rocketsonde Observations of the Middle Atmosphere Dynamics at Uchinoura $\left(31^{\circ} \mathrm{N}, 131^{\circ} \mathrm{E}\right)$ during DYANA Campaign. Part II: Characteristics of Gravity Waves, J. Geomag. Geoelectr., 44, 1009-1023, 1992. 
Vincent, R. A. and D. Lesicar, Dynamics of the equatorial mesosphere: First results with a new generation partial reflection radar, Geophys. Res. Lett., 18, 825-828, 1991.

Vincent, R. A., D. A. Holdsworth, I. M. Reid, and M. A. Cervena, Spaced antenna wind measurements: The effects of signal saturation, in Proceedings of the Workshop on Wind Observations in the Middle Atmosphere, Paris, 15-18 November, 1994.

Widdel, H.-U., Vertical movements in the middle atmosphere derived from foil cloud experiments, J. Atmos. Terr. Phys., 49, 723-741, 1987.

Widdel, H.-U., Foil chaff cloud as a tool for in-situ measurements of atmospheric motions in the middle atmosphere: their flight behavior and implications for radar tracking, J. Atmos. Terr. Phys., 52, 89-101, 1990.

Widdel, H.-U., Experimental evidence for solitary waves in the middle atmosphere, J. Geophys. Res., 96, 15931-15942, 1991.

Widdel, H.-U. and U. von Zahn, Wind corners in the 70-100 km altitude range as observed at Andenes ( $69^{\circ}$ latitude), J. Atmos. Terr. Phys., 52, 995-1015, 1990.
Widdel, H.-U., M. Bittner, and U.-P. Hoppe, Vertical velocities measured at Biscarrosse $\left(44^{\circ} \mathrm{N}\right)$ and by EISCAT at Troms $\emptyset\left(69.6^{\circ} \mathrm{N}\right)$ during the DYANA campaign, J. Atmos. Terr. Phys., 56, 1779-1796, 1994.

Wu, Y.-H. and H.-U. Widdel, Turbulent energy dissipation rates and eddy diffusion coefficients derived from foil cloud measurements, J. Atmos. Terr. Phys., 51, 497-506, 1989.

Wu, Y.-H. and H.-U. Widdel, Saturated gravity wave spectrum in the polar summer lower thermosphere observed by foil chaff during campaign "Sodium 88", J. Atmos. Sci., 49, 1781-1789, 1992.

Yamamoto, M., T. Tsuda, S. Kato, T. Sato, and S. Fukao, Interpretation of the structure of mesospheric turbulence layers in terms of inertia gravity waves, Physica Scripta, 37, 645-650, 1988.

Y. Murayama (e-mail: murayama@crl.go.jp), K. Igarashi, I. Nishimuta, R. Yamazaki, K.-I. Oyama, T. Tsuda, T. Nakamura, S. Fukao, H.-U. Widdel, and K. Schlegel 